\title{
Correction to: Characterization of commercial PLGAs by NMR spectroscopy
}

\author{
Jing Sun ${ }^{1} \cdot$ Jennifer Walker ${ }^{1} \cdot$ Moritz Beck-Broichsitter $^{2} \cdot$ Steven P. Schwendeman ${ }^{1,3}$ \\ Published online: 22 September 2021 \\ (c) Controlled Release Society 2021
}

\section{Correction to: Drug Delivery and Translational Research https://doi.org/10.1007/s13346-021-01023-3}

The order of the polymers has been corrected throughout the original article.

Publisher's Note Springer Nature remains neutral with regard to jurisdictional claims in published maps and institutional affiliations.

The original article can be found online at https://doi.org/10.1007/ s13346-021-01023-3.

Steven P. Schwendeman

schwende@umich.edu

1 Department of Pharmaceutical Sciences and the Biointerfaces Institute, University of Michigan, North Campus Research Complex, 2800 Plymouth Road, Ann Arbor, MI 48109, USA

2 MilliporeSigma a Business of Merck KGaA, Frankfurter Strasse 250, 64293 Darmstadt, Germany

3 Department of Biomedical Engineering, University of Michigan, 2200 Bonisteel Ave, Ann Arbor, MI 48109, USA 